\title{
EXPOSURE AND VULNERABILITY GEOSPATIAL ANALYSIS USING EARTH OBSERVATION DATA IN THE CITY OF LIEGE, BELGIUM
}

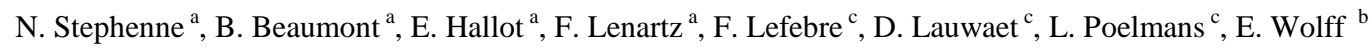 \\ ${ }^{a}$ ISSeP, Remote Sensing and Geodata and Air Quality Monitoring Units, 4000 Liège, rue du Chéra, 200, Belgium - (n.stephenne, \\ b.beaumont, e.hallot, f.lenartz)@issep.be \\ ${ }^{\mathrm{b}}$ ULB, ANAGEO-IGEAT, 1050 Bruxelles, Av. F.D. Roosevelt, CP 130/03, Belgium - ewolff@ulb.ac.be \\ ${ }^{\mathrm{c}}$ VITO, $2400 \mathrm{Mol}$, Boeretang, 200, Belgium - (filip.lefebre, dirk.lauwaet, lien.poelmans)@ vito.be
}

KEY WORDS: Vulnerability, Exposure, Earth Observation, Land Cover / Land Use, Urban Heat Island, Air Pollution, City Models ABSTRACT:

Risk situation can be mitigated by prevention measures, early warning tools and adequate monitoring of past experiences where Earth Observation and geospatial analysis have an adding value. This paper discusses the potential use of Earth Observation data and especially Land Cover / Land Use map in addressing within the three aspects of the risk assessment: danger, exposure and vulnerability. Evidences of the harmful effects of air pollution or heat waves are widely admitted and should increase in the context of global warming. Moreover, urban areas are generally warmer than rural surroundings, the so-called urban heat island. Combined with in-situ measurements, this paper presents models of city or local climate (air pollution and urban heat island), with a resolution of less than one kilometer, developed by integrating several sources of information including Earth Observation data and in particular Land Cover / Land Use. This assessment of the danger is then be related to a map of exposure and vulnerable people. Using dasymetric method to disaggregate statistical information on Land Cover / Land Use data, the SmartPop project analyzes in parallel the map of danger with the maps of people exposure A special focus on some categories at risk such as the elderly has been proposed by Aubrecht and Ozceylan (2013). Perspectives of the project includes the integration of a new Land Cover / Land Use map in the danger, exposure and vulnerability models and proposition of several aspects of risk assessment with the stakeholders of Wallonia.

\section{INTRODUCTION}

\subsection{Remote sensing in urban risk analysis}

No technology can prevent natural hazards. However, the risk situation can be mitigated by prevention measures, early warning tools and adequate monitoring of past experiences where remote sensing and geospatial analysis have an adding value (Deleu et al., 2011). In the context of climate change and urban growth, our attention is focused on cities which are concentrating both the population as well as specific hazards such as urban heat and air pollution. This paper discusses the potential use of remote sensing data and geospatial modelling approaches for addressing the risk equation for the city of Liège within the three aspects: danger, exposure and vulnerability (IPCC, 2012).

Integration of Earth Observation (EO) with existing in-situ and statistical information in simulation models helps to better understand, localise and learn from past experiences to prevent impact of future events. These data proved their usefulness in the three aspects of the risk equation. Firstly, remote sensing information is used for mapping danger occurrence (Nayak and Zlanatova, 2008) and specifically danger of flood (Chormanski et al., 2011), earthquake (Tralli et al., 2005), air pollution (Martin, 2008; Prud'homme et al., 2013) or urban heat (Aubrecht and Ozceylan, 2013). Secondly, assets and built-up area are estimated according to various urbanization definition and settlements maps using EO data (Aubrecht et al., 2016, Pesaresi et al., 2016). The link to population and then risk exposure is established by dasymetric mapping methods integrating Land Use (LU) data derived from EO data. However, population vulnerabilities, which are hazard and context dependent and refer to exposed element at risk, is however still a challenging research avenue (Peduzzi et al., 2009; Ebert et al., 2009; Birkmann, at al., 2013). Remote sensing analysis has been envisaged to update and improve the Land Cover (LC) and LU data (Grippa et al., 2017). In this paper, we propose to discuss this dataset as an input of danger models, exposure models and vulnerability ones. These three steps in targeting the risk are envisaged in the different parts of this paper, respectively the state of the art, the existing data and model and the results.

Knowing firstly where the danger is occurring, then where people or assets are and, finally, if these people or assets are vulnerable to this specific danger are three major research questions that are important for risk mitigation. Our particular interest refers to the context of climate change and urban growth in the Walloon Region of Belgium, hereinafter referred to as Wallonia. Regional and city levels should be explored in a multi-level approach (Aubrecht et al., 2013) but this paper discusses our first methodological frame on the city of Liège.

To address the first question, we propose LU maps derived from EO data to be introduced in models such of air quality or urban heat island (UHI). For the second question, building or impervious maps are the input of population density models combining demographic data from statistical sources with LU information using EO data. For addressing the third question, a spatial link to identify people at risk of air pollution or urban heat is related to population data as an initial step to other socio-economic statistics of situation specific to human exposure and vulnerability (Aubrecht et al., 2013). According to these authors, social and economic vulnerability indicators should be discussed for urban specific risk patterns. This paper 
proposes the framework of the complete chain toward risk assessment with only one variable in the final vulnerability assessment. The authors will build on this first example to further develop the approach.

\subsection{Air pollution}

Recent scientific evidence of the harmful effects of air pollution on health were widely reviewed and discussed in several reports (WHO, 2013a and 2013b; IARC, 2013; EEA/JRC, 2013; APHEKOM, 2012). Air pollution was classified by the International Agency for Research on Cancer (IARC) in 2013 as carcinogenic to humans. Moreover, the positive association between air pollution and increased risk of bladder cancer has also been reported. Furthermore, air pollution increases the risk of several types of diseases, such as respiratory and hearth diseases.

Specifically, according to the EEA/JRC (2013), particulate matter is one of the most relevant air pollutants related to health problems and premature death. Particulate matters are related to various sicknesses: asthma, bronchitis and other chronic pulmonary disease, lung cancer, cardiovascular disease and birth problems (WHO, 2005; EEA/JRC, 2013). They can than reduce life expectancy and increase mortality.

Epidemiological studies have shown adverse health effects related to NOx: reduced lung function, asthma and cardiovascular and respiratory mortality and morbidity (WHO, 2013a). Children are particularly sensitive to pollution to NOx (EEA/JRC, 2013).

Finally, several long-term effects related to ozone pollution have been reported: asthma, alteration of lung function development in children, immune reactions, premature births (EEA, 2013; WHO, 2013a; Curtis et al., 2006). This pollution is also particularly dangerous for children, the elderly or people with chronic pulmonary and hearth disease.

\subsection{Heat waves and Urban Heat Islands (UHI)}

In the context of climate change and global warming, there is a growing concern about extreme heat events that have been reported as a leading cause of weather-related mortality (Aubrecht and Ozceylan, 2013). Urban areas are generally warmer than their rural surroundings, the so-called UHI (Lauwaet et al., 2016). The built-up environments contain large areas of impervious surfaces with increased thermal inertia (Chen et al., 2017), while also inhibiting evaporative cooling. This causes cities to experience higher air temperatures than rural areas, with night-time temperature differences up to $10^{\circ} \mathrm{C}$. Because of the UHI increment, cities are particularly vulnerable to heat waves, with higher heat-related excess mortalities (Vandentorren et al., 2004). The fast urbanization of cities causes and aggravates microclimate and thermal discomfort, deteriorates air quality and increases noise levels (Cohen et al., 2014).

\subsection{Exposure and vulnerability}

It is increasingly recognized that threats to human security cannot be reduced solely on hazards (Birkmann at al., 2013). According to these authors, societies will have to live with changing environmental conditions and therefore need to build resilience by reducing vulnerabilities to natural hazards. Vulnerability assessment is a multidisciplinary research avenue and various definitions exist. According to IPCC (2012), the exposure is the presence of people, livelihoods, environmental services and resources, infrastructure, or economic, social, or cultural assets in places that could be adversely affected. The vulnerability is the propensity or predisposition to be adversely affected. We can distinguish quantitative and qualitative approaches to address vulnerability. The quantitative approach is usually related to natural and social sciences (Birkmann et al., 2013). They quantify damage ranges to help determining acceptable level of potential losses. The MOVE framework differentiates risk from vulnerability and integrates the concept of adaptation.

The geospatial estimation of risk, exposure and vulnerability generally relies on geographical information system (GIS) based approaches (Tatem et al., 2014; SIGENSA). Such approaches enable the construction and combination of spatial data and indicators, including population distributions and characteristics (gender, age, income) and hazard sources, to model exposure and vulnerability and to spatially quantify risks. GIS based modelling allows mapping exposure to multiple hazards (Perduzzi et al., 2009) and are pertinent at both global, national or regional scales. A national scale example is given by Ebert et al. (2009) who used LC proxies derived from a contextual object-oriented analysis of EO and GIS data to assess social vulnerability in Honduras.

Establishing who is the most at risks for a specific danger such as heat stress is a complex issue involving a combination of location dependant physiological variables as well as other social and environmental factors (Aubrecht and Ozceylan, 2013). These authors state that elderly adults and seniors ages above 60 are most strongly affected by extreme heat, population that should increase in the next 30 years. The excess mortality from heat waves is related to cardiovascular, cerebrovascular and respiratory causes. However, the elderly are not the only one at risk as people suffering from diabetes, neurological disorders as well as economically and socially marginalized are also vulnerable.

\section{DATA}

The current research is focused on the area surrounding the city of Liège, Belgium (Figure 1). European and regional source of information are analysed to address the aspects of the risk equation. However as vulnerability information should be danger and context specific, there are not integrated in this review of existing data.

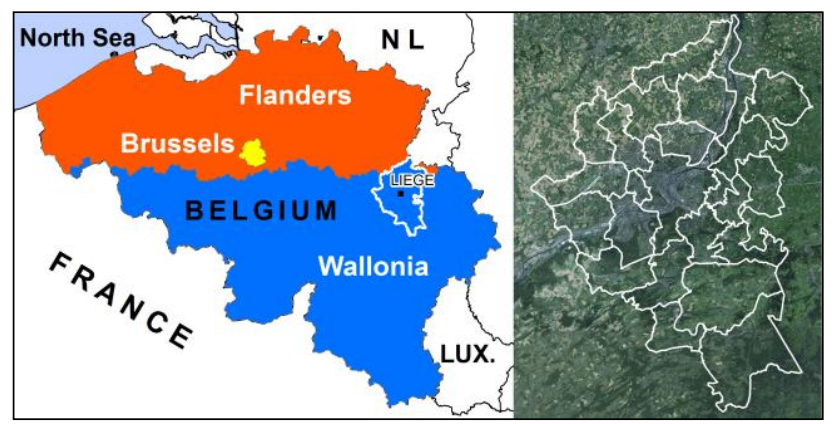

Figure 1. Area of Interest: Wallonia, Belgium (left); Liège district with 24 municipalities (right) 


\subsection{Land Cover / Land Use information}

The LC/LU map of Wallonia (COSW) has not been updated since 2007. This dataset integrates several sources from 2005 and sooner (Baltus et al., 2007). All available thematic data sources have been integrated into an unique 'use' and 'cover' legend inspired from the European CORINE Land Cover (CLC) map. The hierarchy legend of classes presents five thematic layers divided in 71 classes with a mix of LU and LC definitions.

\subsection{Air pollution monitoring}

The Scientific Institute of Public Services (ISSeP) manages a real-time assessment network of ambient air quality. Collecting data on a semi-hourly basis, this network is used to inform the authorities and the public on air quality levels. There are about 20 stations measuring the major atmospheric pollutants in Wallonia: $\mathrm{PM}_{\mathrm{x}}, \mathrm{NO}_{2}$ and $\mathrm{O}_{3}$. If such a number allows one to map background levels, it remains non-trivial to accurately map these parameters for the whole region, cities included.

\subsection{Urban Heat Islands delineation}

As stated by Chen et al. (2017), atmospheric UHI are normally measured by in situ air temperature sensors. However, while the Surface UHI (SUHI) refers to the excess warmth of urban areas compared with their non-urbanized surroundings, it can be measured by Land Surface Temperature (LST) levels observed by thermal infrared remote sensing. The estimation of the thermal inertia of an earth surface object is dependent on two factors: the albedo and diurnal LST variation. Using SPOT and MODIS satellite images captured over a period of 17 years, Chen et al. (2017) demonstrated that diurnal LST variation increases with urbanization. These kind of studies can help to define the measures that can reduce urban heat absorption such as urban parks, community green spaces, green roofs and cool or permeable pavements, in order to mitigate UHI effects.

\subsection{Quantification of the exposure}

Addressing quantitatively the elements potentially affected by a danger refers to damage, human loss and economic loss (De Groeve et al., 2015). These last can be intangible and can be referenced and recorded at the house, municipality, province or country level. Urban or built-up areas are then an element at risk for specific infrastructure and assets but are also considered as a proxy of the presence of people. There are several approaches addressing spatial delineation of urban areas but remote sensing data and derived products are an important category (Aubrecht et al., 2016). Satellite-observed night-time lights data was the first potential proxy in the early 1970s (Sutton, 1997). Artificial surfaces or built-up areas derived from EO data are an alternative proxy with the Global Urban footprint GUF) (Esch et al., 2012) or the Global Human Settlement layer (GHSL) (Pesaresi et al., 2016).

De Groeve et al. (2015) identify people as social affected element, building / infrastructures / industries as economic elements, protected areas as environmental elements, and cultural or historical assets such as heritage elements. In Wallonia, the PICC (geoportail.wallonie.be) represents several elements (Figure 2). For updating this dataset, EO data are progressively envisaged by regional authorities.

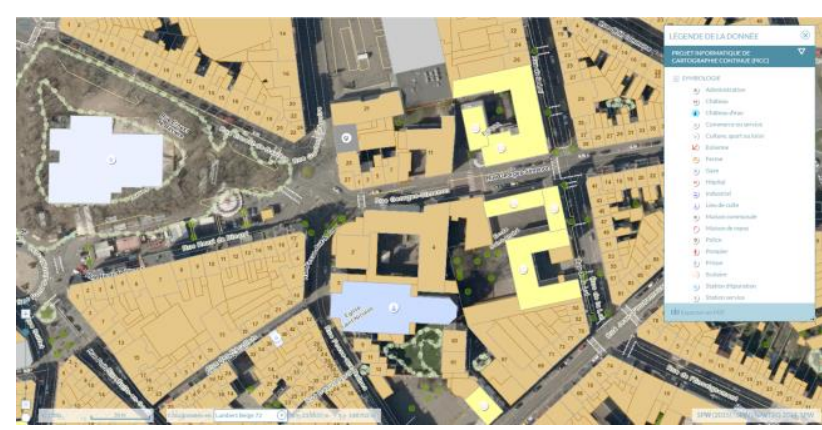

Figure 2. Extract of the PICC in the center of Liège (geoportail.wallonie.be)

Mapping the presence of people or population distribution has been improved by innovative dasymetric technique (Petrov, 2012). Dasymetric mapping techniques use ancillary information to distribute the statistical data in homogenous spatial zones and increase spatial accuracy (Eicher and Brewer, 2001). Traditionally, population density is based on data provided at administrative units scale by national statistical institutes, showing the density in terms of inhabitants per unit. At the European level, a population map has been developed by Gallego and Peedell (2001). They disaggregate official European population counts (for the year 2000) into $100 \mathrm{~m}$ cells using EO CLC as main ancillary data. More detailed and updated spatial data can produce reliable estimates of cell-level information for both population and economics activities (White et al., 1997). For Wallonia's application, population numbers for the period 2008-2015 are taken from the National Statistical Institute (2011).

\section{METHODS AND RESULTS}

Most of the preceding and following methods integrate remote sensing information to geographically localise the different research questions through geospatial analysis. Buildings, road density, LC/LU or proportion of impervious surfaces can be derived from remote sensing data and introduced as input in models.

\subsection{Land Cover/Land Use mapping methodology}

SmartPop project proposes a semi-automated object-oriented image analysis (OBIA) method for detailed regional urban LC mapping (Beaumont et al., submitted). This paper focuses on the precise characterization of complex urban LC using submeter resolution EO data. The challenges of the so called 'salt and pepper effect', the classification confusion between buildings and roads or water and shadows are discussed and two OBIA approaches are compared in terms of automation, transferability and objectivity. The first one consists of two steps: first, a segmentation of the image and secondly, a classification of the generated objects with supervised machinelearning classifiers. The second OBIA approach uses expert knowledge to define the hierarchical rules that simultaneously segment and classify images. SmartPop analyses the opportunities of a multi-source data fusion to improve urban LC mapping. We combine optical data with height related features from Light Detection And Ranging (LiDAR). Ancillary vector data can also successfully constrain the segmentation and classification steps to improve the mapping accuracies.

In the SmartPop project, we compare the advantages of aerial images versus sub-meter satellite imagery (Pleiades) not only in 
term of classification accuracy but also in terms of costs, preprocessing, data availability and property rights. The annual acquisition of aerial orthophotos, planned for Wallonia, is an advantage for the development of operational methods. In fact, our acquisition of Pleiades data demonstrated that the framework to obtain pre-processed satellite data is not straightforward and costs more in our region. Waiting times to get access to the data is however shorter for satellite imagery, aerial coverage usually being made available around 6 months to one year after data acquisition. Based on this new SmartPop LC map (Figure 3b), a LU methodology is currently developed in the same approach as the COSW data (Figure 3a) by integrating existing datasets.
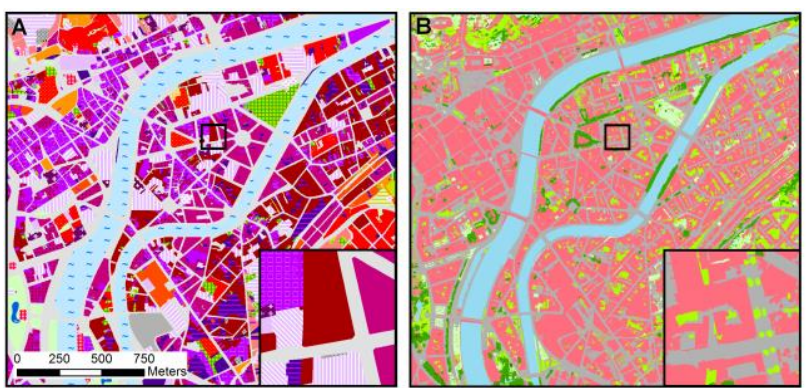

Figure 3. (a) Existing LU map in 71 classes (COSW2007) and (b) new LC map by OBIA in 9 classes (SmartPop)

\subsection{Model of air pollution}

In the SIGENSA project, we integrated spatial and quantitative analysis of environmental pressures related to citizens' health problems (Stephenne et al., 2013). For this model, the air pathway integrates four factors geospatially integrated on 3-year average concentration for the 4 main pollutants of ambient air $\left(\mathrm{O}_{3}, \mathrm{NO}_{2}, \mathrm{PM}_{2.5}\right.$ and $\left.\mathrm{PM}_{10}\right)$. This simple approach can largely be improved by integrating local aspect in the interpolation model. RIO interpolation model has been developed to incorporate both the regional and local aspects of the air pollution phenomenon and produce concentration estimates on a $4 \times 4 \mathrm{~km}^{2}$ grid (Janssen et al., 2008). To deal with the local scale of the air pollution phenomenon, this model links emission levels to LU patterns at the same local scale. The PM-Lab model adds the roughness length in the LU indicator to indirectly take into account wind speed and provide values on a $1 \times 1 \mathrm{~km}^{2}$ grid (Merbitz et al., 2012) (Figure 4). This model developed in the framework of an Interreg program has been transposed to Wallonia and adapted to other pollutants than $\mathrm{PM}_{10}$. The new LU map of SmartPop will be integrated in the model and the benefits will be estimated through leave-one-out exercises.

\subsection{Model of Urban heat Island}

When the network of temperature sensors has an insufficient coverage to delineate UHI, an alternative and indirect approach is the modelling of city climate by regional climate models (RCM). A RCM at $25 \mathrm{~km}$ resolution coupled with an urban land-surface scheme can help to assess the sensitivity of urban climate to climate change (McCarthy et al., 2012). However, the spatial resolution of these climate models cannot assess the urban-scale problems, for which a $1 \mathrm{~km}$ or even higher resolution is required (Lauwaet et al., 2016). Therefore, in this study we apply a high resolution $(100 \mathrm{~m})$ urban climate model which uses several sources of EO data as input.

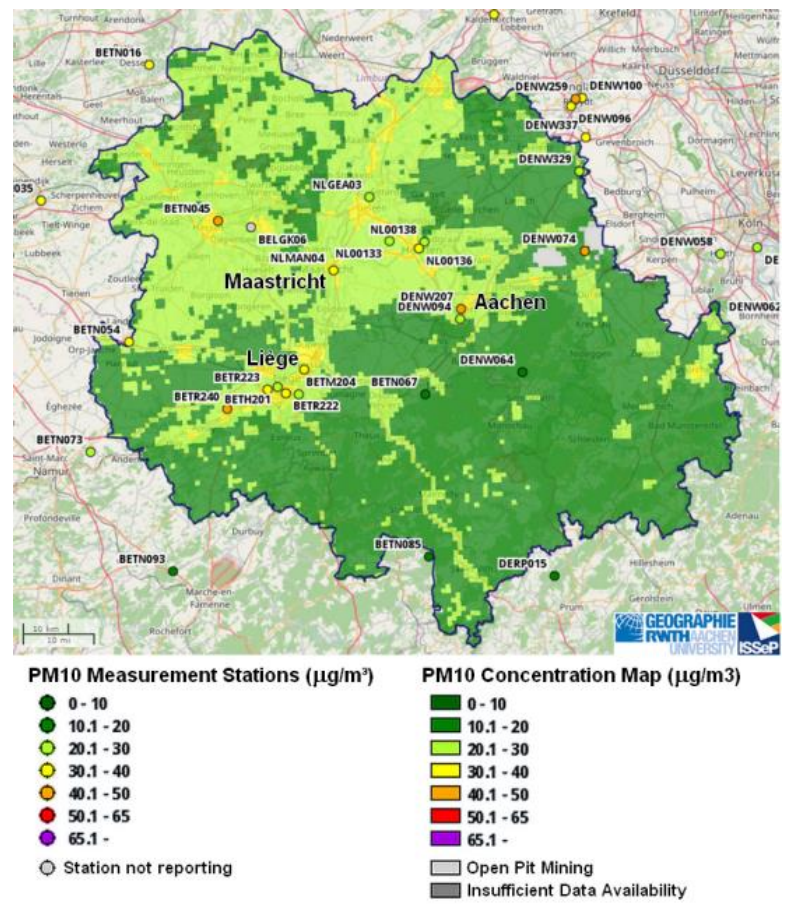

Figure 4. Map from http://pmlab.irceline.be (modified)

The urban boundary layer climate model "UrbClim" is designed to cover individual cities and their nearby surroundings at a very high spatial resolution (De Ridder et al., 2015). The previous paper describes the parameters and outputs of this model. UrbClim consists of a land surface scheme containing simplified urban physics, coupled to a 3D atmospheric boundary layer module. The land surface scheme is based on the soil-vegetation-atmosphere transfer scheme of De Ridder and Schayes (1997), but is extended to account for urban surface physics. This urbanization is accomplished in a rather simple way, by representing the urban surface as a rough impermeable slab, with appropriate values for the albedo, emissivity, thermal conductivity and volumetric heat capacity.

This model uses several sources of EO data. The spatial distribution of LC types, needed for the specification of required land surface parameters, is taken from the CLC data for Europe (European Commission, 1994). The percentage urban LC is specified using the Urban Soil Sealing raster data files distributed by the European Environment Agency. Maps of vegetation cover fraction are obtained from the Normalized Difference Vegetation Index (NDVI) acquired by the MODIS instrument on-board of the TERRA satellite platform. Vegetation cover fraction is specified as a function of the NDVI using a linear relationship proposed by Gutman and Ignatov (1998), and then interpolated to the model grid.

Within the FP7 RAMSES project, UrbClim was applied for the city of Liège in Wallonia (Figure 5f). A demonstration simulation was set up for the summer of 2011 with a spatial resolution of $250 \mathrm{~m}$, directly driven with meteorological data from the ERA-Interim reanalysis of the European Centre for Medium-range Weather Forecasting (ECMWF), as was the setup in previous validation experiments (De Ridder et al., 2015). The UrbClim model has been successfully validated regarding its energy fluxes, $2 \mathrm{~m}$ air temperatures and urban-rural temperature differences for the cities of Antwerp, Brussels and 
Ghent in Belgium (De Ridder et al., 2015; Lauwaet et al., 2016), yielding comparable or better validation statistics than full-blown regional climate models.

\subsection{Model of population distribution}

Based on LC/LU maps, the SmartPop project aims to provide recurrent population distribution maps for analyzing the city development and the presence of people (Stephenne et al., 2016). The WEISS software dasymetric mapping module distributes the population statistics over the different LC/LU classes of the COSW given a specific weight for each class calculated in terms of relative population density (Poelmans et al., 2015). While this protocol is executed per district, the demographical data provided at the level of the statistical sectors are aggregated at this level. We derived two types of information from the COSW: classes of density of non-urban LC/LU categories, and relative density of each of these classes (weights) (Hallot et al., 2016). For calibration, we used the aggregated version of the National Register of Natural Persons (RNPP) dataset which localises the exact number of people per houses (SPF Interieur, 2016). For privacy reasons, the Walloon Institute for Statistical Evaluation and Prospective (IWEPS) built this aggregated version of these data in raster format with a $100 \times 100 \mathrm{~m}$ resolution. The dasymetric mapping result are illustrated for the city of Liege on Figure 5(a, b, c, d, e) with a $50 \times 50 \mathrm{~m}$ resolution more suitable for high population density areas.

\subsection{Example of vulnerable population}

As proposed by Aubrecht and Ozceylan (2013), elderly adults and seniors ages above 65 are potentially most strongly affected by the danger of UHI or air pollution. At the level of the statistical sectors, the National Statistical Institute provides information about gender, number of households, number of foreigners and different classes of age. Through the dasymetric module, we then produce data about the specific areas where elderly people are precisely localised with distinction of gender (Figure 5 b, c, d).

\section{CONCLUSIONS AND DISCUSSIONS}

A detailed and accurate knowledge of LC is crucial for many scientific and operational applications, and as such, it has been identified as an Essential Climate Variable (Inglada et al., 2017). Requested by the EU directive, this map is needed for city or regional spatial planning and for management of citizen well-being related to environmental changes. As described in this paper, this LC/LU information is also used in all the steps of the risk assessment. Urban planners and environmental monitoring stakeholders of Wallonia still rely on outdated or incomplete LC/LU information. The SmartPop project then developed a methodology for a Walloon LC map. We are currently developing the LU methodology by integrating ancillary information to this LC basic map. While this LC/LU map is essential for spatial planning at regional and local scale, it is also an essential input for the modelling of air pollution, UHI, exposure and vulnerability.

Earth Observation is the main input of LC/LU and the new Copernicus data policy provides an opportunity of regularly updating this dataset. According to Inglada et al. (2017), the availability Sentinel-2 imagery with its unique characteristics (290 km swath, 10 to $60 \mathrm{~m}$ spatial resolution, 5-day revisit cycle with 2 satellites, 13 spectral bands) will enable the implementation of LC map production systems for the delivery of up to date and accurate information with the appropriate timeliness. While these new EO data offer new opportunities for national LC/LU and faster production of CLC, they will perhaps not address all the needs of local authorities which have requested a more precise resolution. SmartPop project has identified a list of end-users and involve them closely in the project development process to precisely define the specific goals and outcomes for Wallonia. This regular interaction with an implementation group including scientists and decision makers from several administrations help us to focus on the right legend, the right resolution and the final output for different objectives from spatial planning to risk prevention and mitigation (Beaumont et al., 2016). A survey has assessed the users' satisfaction regarding the existing Walloon LU map as well as the expectation towards the new products which are integrated in the LC/LU methodology.

Floods, air pollution, UHI, mobility issues and other environmental and health risks increase with urban growth. In Wallonia, the increasing trend of these risks is driven by high current and projected urbanization rate. Sustainable territory planning requires a dynamic vision of the fast changing environment. This can be done through regular update of LC/LU, in situ measurements, models of danger, exposure and vulnerability but also scenarios or simulation of these risks in the future. Prospective analysis of LC/LU till 2050 using Cellular Automata model provide spatially explicit scenarios of LC/LU and population density which are important to adapt current planning policies to future trends (Beaumont et al., 2016).

Until now, SmartPop project addressed only the population exposure by dasymetric methods producing population density map disaggregating demographic figures on this LC/LU map. As proposed by De Groeve et al. (2015), we will also derive from ancillary dataset a list of elements potentially affected. While this approach is parallel to the integration of LU in the LC map, the discussions with the implementation group of Wallonia will address this aspect of exposure in the next months.

For vulnerability assessment, this paper has proposed a simple disaggregation of one specific class of people: the elderly. While these spatial approaches provide interesting tools to visualize in parallel the area where the vulnerable people are supposed to live and the potential risks related to air pollution or UHI, epidemiological studies are needed to analyse and discuss in detail these links. As discussed by Aubrecht and Ozceylan (2013), socio-economic characteristics as well as environmental pressures can increase the vulnerability. These aspects will be further analysed in the SmartPop project.

\section{ACKNOWLEDGEMENTS}

The research pertaining to these results received financial aid from (i) ISSeP Moerman's fund and (ii) from Beslpo (Belgian Science Policy Office) in the frame of the STEREO III program - project SmartPop no. SR/00/313. Service Public de Wallonie is acknowledged for providing aerial orthophotos, LiDAR and ancillary vector geodatabases (LIC \#160128-1348, all rights reserved to SPW). Authors thank all members of SmartPop scientific and steering committees for their involvement in the implementation group. 


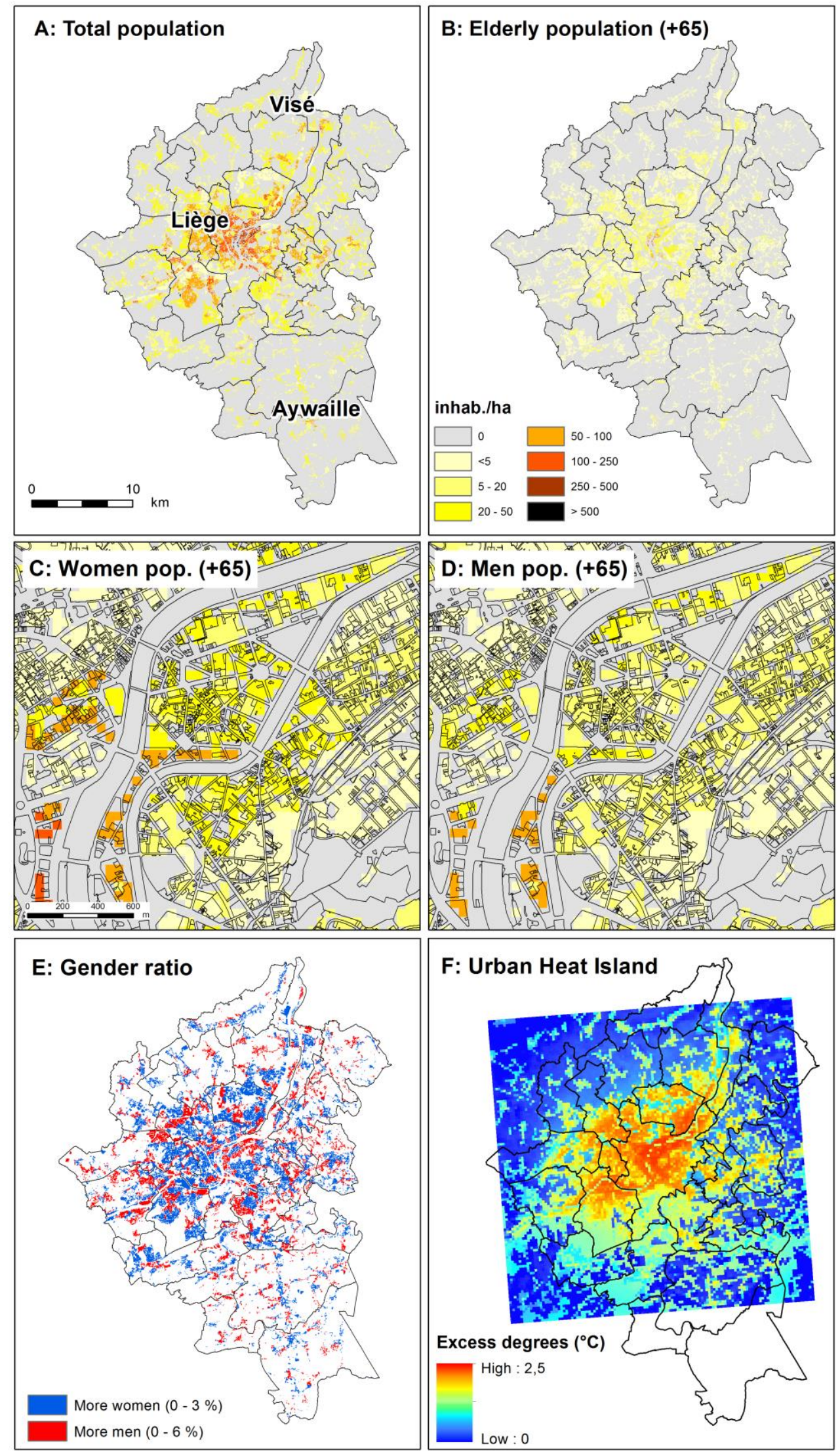

Figure 5. (a) Total population; (b) Elderly population (over 65 years); (c) Zoom on female population over 65 ; (d) Zoom on male population over 65 ; (e) Total population gender ratio; (f) Urban Heat Island (data from https://www.urbanclimate.eu/services/eu_cities, 2011 summer, 250m spatial resolution) 


\section{REFERENCES}

APHEKOM, 2012. Summary report of the Aphekom project 2008-2011, 12 p.

Aubrecht, C., Gunasekera, R., Ungar, J. \& Ishizawa, O., 2016. Consistent yet adaptive global geospatial identification of urban-rural patterns: The iURBAN model. Remote Sens. Environ. 2016, 187, pp. 230-240.

Aubrecht, C. \& Ozceylan, D., 2013. Identification of heat risk patterns in the U.S. National Capital Region by integrating heat stress and related vulnerability. Environ. Int. 2013, 56, pp. 6577.

Aubrecht, C., Ozceylan, D., Steinnocher, K. \& Freire, S., 2013. Multi-level geospatial modeling of human exposure patterns and vulnerability indicators. Nat. Hazards 2013, 68, pp. 147163.

Baltus, C., Lejeune, P. \& Feltz, C., 2007. Mise en œuvre du projet de cartographie numérique de l'Occupation du Sol en Wallonie (PCNOSW), Faculté Universitaire des Sciences Agronomiques de Gembloux.

Beaumont, B., Grippa, T., Lennert, M., Vanhuysse, S., Stephenne, N. \& Wolff, E. (ongoing). Towards an operational and detailed urban land cover mapping in Wallonia using submeter remote sensing and ancillary vector data.

Beaumont, B., Stephenne, N., Wolff, E., Poelmans, L. \& Baltus C., 2016. User participation in SmartPop methodology of updating the Walloon Land Use Land Cover map. ESA Living Planet Symposium Prague (May 2016).

Birkmann, J., Cardona, O. D., Carreño, M. L., Barbat, A. H., Pelling, M., Schneiderbauer, S., Kienberger, S., Keiler, M., Alexander, D., Zeil, P. \& Welle, T., 2013. Framing vulnerability, risk and societal responses: The MOVE framework. Nat. Hazards 2013, 67, pp. 193-211.

Chen, Y. C., Chiu, H. W., Su, Y. F., Wu, Y. C. \& Cheng, K. S., 2017. Does urbanization increase diurnal land surface temperature variation? Evidence and implications. Landsc. Urban Plan. 2017, 157, pp. 247-258.

Chormanski, J., Okruszko, T., Ignar, S., Batelaan, O., Rebel, K. T. \& Wassen, M. J., 2011. Flood mapping with remote sensing and hydrochemistry: A new method to distinguish the origin of flood water during floods. Ecol. Eng. 2011, 37, pp. 1334-1349.

Cohen, P., Potchter, O., Schnell, I., 2014. The impact of an urban park on air pollution and noise levels in the Mediterranean city of Tel-Aviv, Israel. Environ. Pollut. 2014, 195, pp. 73-83.

Curtis, L., Rea, W., Smith-Willis, P., Fenyves, E. \& Pan, Y, 2006. Adverse health effects of outdoor air pollutants, Environment International, 32, pp. 815-830.

De Groeve, T., Corbane C. \& Ehlrich, D., 2015. Guidance for Recording and Sharing Disaster Damage and Loss Data. Publications Office of the European Union, Luxembourg, 27 p.

De Ridder, K., Lauwaet, D. \& Maiheu, B., 2015. UrbClim - a fast urban boundary layer climate model. Urban Climate 12, pp. 41-58.
De Ridder, K. \& Schayes, G., 1997. The IAGL Land Surface Model, J. Appl. Meteorol., 36, pp. 167-182.

Deleu, J., Tambuyzer, H. \& Stephenne, N., 2011. Multi Risk Preparedness Supported by Earth Observation. Gi4DM 2011, Conf. Antalya (03-08 May).

Ebert, A., et al., 2009. Urban social vulnerability assessment with physical proxies and spatial metrics derived from air and spaceborne imagery and GIS data. Natural Hazards, 48(2), 275294.

EEA/JRC, 2013. Environment and human health, EEA report $\mathrm{n}^{\circ} 5$.

Eicher, C., \& Brewer C., 2011. Dasymetric mapping and areal interpolation: Implementation and evaluation. Cartography and Geographic Information Science, 28, pp. 125-138.

Esch, T., Taubenböck, H., Roth, A., Heldens, W., Felbier, A., Thiel, M., Schmidt, M., Müller, A., \& Dech, S., 2012. TanDEM-X mission - new perspectives for the inventory and monitoring of global settlement patterns. In: Journal of Applied Remote Sensing, Vol. 6, Issue 1, pp. 1-21.

European Commission, 1994. CORINE Land Cover Technical Guide, EUR 12585 EN. European Commission Publications, Luxembourg, 35p.

Gallego, F. J. \& Peedell, S., 2001. Using Corine Land Cover to map population density. In European Environment Agency. "Towards agri-environmental indicators: Integrating statistical and administrative data with land cover information". Copenhagen, pp. 94-105.

Grippa, T., Lennert, M., Beaumont, B., Vanhuysse, S., Stephenne, N. \& Wolff, E. (submitted). An open-source semiautomated processing chain for urban OBIA classification. Remote Sens. (accepted)

Gutman, G. \& Ignatov, A., 1998. Derivation of green vegetation fraction from NOAA/AVHRR for use in weather prediction models. Int. J. Remote Sens. 19, pp. 1533-1543.

Hallot, E., Poelmans, L., Uljee, I., Beaumont, B. \& Stephenne, N., 2016. Localiser la population urbaine pour optimiser la gestion du territoire. Acte de colloque des 34èmes Rencontres Universitaires de Génie Civil de l'AUGC, Liège, Belgium (May 2016).

IARC, 2013. Press Release $n^{\circ} 221$, Outdoor air pollution a leading environmental cause of cancer deaths, OMS, 4 p.

Inglada, J., Marcela Arias, A. V., Tardy, B., Morin D. \& Rodes, I., 2017. Operational High Resolution Land Cover Map Production at the Country Scale Using Satellite Image Time Series, Remote Sens. 2017, 9(1), 95.

Institut National des Statistiques, 2011. Census 2011, SPF Economie, http://statbel.fgov.be. Accessed July 2016.

IPCC, 2012. Managing the Risks of Extreme Events and Disasters to Advance Climate Change Adaptation. A Special Report of Working Groups I and II of the Intergovernmental Panel on Climate Change. Cambridge University Press, Cambridge, $582 \mathrm{p}$. 
Janssen, S., Dumont, G., Fierens, F. \& Mensink, C., 2008. Spatial interpolation of air pollution measurements using CORINE land cover data. Atmospheric Environment 42 (20), pp. 4884-4903.

Lauwaet, D., De Ridder, K., Saeed, S., Brisson, E., Chatterjee, F., van Lipzig, N. P. M., Maiheu, B. \& Hooyberghs, H., 2016. Assessing the current and future urban heat island of Brussels. Urban Clim. 2016, 15, pp. 1-15.

Martin, R. V., 2008. Satellite remote sensing of surface air quality. Atmos. Environ. 2008, 42, pp. 7823- 7843.

McCarthy, M. P., Harpham, C., Goodess, C. M. \& Jones, P. D., 2012. Simulating climate change in UK cities using a regional climate model, HadRM3. Int. J. Climatol. 2012, 32, pp. 18751888 .

Merbitz H. F., Detalle, F., Ketzler, G., Schneider, C. \& Lenartz, F., 2012. Small scale particulate matter measurements and dispersion modelling in the inner city of Liège, Belgium, International Journal of Environment and Pollution, 30 $(1 / 2 / 3 / 4)$, pp. 234-249.

Nayak, S. \& Zlatanova, S., 2008. Remote sensing and GIS technologies for monitoring and prediction of disasters. Springer-Verlag Berlin Heidelberg, 272 p.

Peduzzi, P. et al., 2009. Assessing global exposure and vulnerability towards natural hazards: the Disaster Risk Index. Natural Hazards and Earth System Sciences, 9(4), 1149-1159.

Pesaresi, M., Melchiorri, M., Siragusa, A. \& Kemper, T., 2016. Atlas of the Human Planet, Publications Office of the European Union, $137 \mathrm{p}$.

Petrov, A., 2012. One Hundred Years of Dasymetric Mapping: Back to the Origin. The Cartographic Journal, 49, pp. 256-264.

Poelmans, L., White, R., Engelen G. \& Uljee, I., 2015. Modeling in Support of Spatial Planning and Policy Making: The example of Flanders, 11, in Modeling Cities and Regions as Complex Systems, White R. et al. eds., The MIT Press, 330 p.

Prud'homme, G., Dobbin, N. A., Sun, L., Burnett, R. T., Martin, R. V., Davidson, A., Cakmak, S., Villeneuve, P. J., Lamsal, L. N., van Donkelaar, A., Peters, P. A. \& Johnson, M., 2013. Comparison of remote sensing and fixed-site monitoring approaches for examining air pollution and health in a national study population. Atmos. Environ., 80, pp. 161-171.

Stephenne N., Poelmans, L., Hallot, E., Beaumont B. \& Uljee, I., 2016. From regional LULC model to urban population density simulation in Wallonia. Eurographics Workshop on Urban Data Modelling and Visualisation. Liège, Belgium (0812).

SPF Intérieur, 2016. Direction générale Institutions et Population, http://www.ibz.rrn.fgov.be/fr (2014). Accessed July 2016.

Stephenne N., Remy S., Eloy S., Stassen F. \& Defoux J., 2013. A Walloon spatial simulation model of risk in environment and health, in Brebbia C. and Kiss R. (eds), Environmental health Risk VII, WITPress, England, pp 35-46.
Sutton, P., Roberts, D., Elvidge, C. \& Meij, H., 1997. A Comparison of Nighttime Satellite Imagery and population Density for the Continental United States. Photogrammetric Engineering and Remote Sensing, 63, pp. 1303-1313.

Tatem, A.J. et al., 2014. Mapping for maternal and newborn health: the distributions of women of childbearing age, pregnancies and births. International Journal of Health Geographics, 13(2), 11pp.

Tralli, D. M., Blom, R. G., Zlotnicki, V., Donnellan, A. \& Evans, D. L., 2005. Satellite remote sensing of earthquake, volcano, flood, landslide and coastal inundation hazards. ISPRS J. Photogramm. Remote Sens., 59, pp. 185-198.

Vandentorren, S., Suzan, F., Medina, S., Pascal, M., Maulpoix, A., Cohen, J-C. \& Ledrans, M., 2004. Mortality in 13 French Cities During the August 2003 Heat Wave. Am J Public Health. 2004 September; 94(9). pp. 1518-1520.

White R., Engelen G. \& Uljee, I., 1997. The use of constrained cellular automata for high-resolution modelling of urban landuse dynamics, Environment and Planning B: Planning and Design, SAGE Publications, 24, 3, pp. 323-343.

WHO, 2005. WHO Air Quality Guidelines, Global Update 2005, Copenhagen, Denmark, 30 p.

WHO, 2013a. Evidence on Health Aspects of Air Pollution to Review EU Policies, REVIHAAP, Technical Report, Copenhagen, Denmark, 309 p.

WHO, 2013b. Health risks of air pollution in Europe HRAPIE project, Technical Report, Copenhagen, Denmark, $65 \mathrm{p}$. 